\title{
Phytopathology
}

\section{Cyclophilins: Less Studied Proteins with Critical Roles in Pathogenesis}

\author{
Khushwant Singh, ${ }^{\dagger}$ Mark Winter, Miloslav Zouhar, and Pavel Ryšánek
}

\begin{abstract}
First author: Division of Crop Protection and Plant Health, Crop Research Institute, Drnovská 507, 16106 Prague, Czech Republic; first and second authors: Plant Pathology and Crop Protection Division, Department of Crop Sciences, Faculty of Agriculture, Georg-AugustUniversity Göttingen, Germany; and first, third, and fourth authors: Department of Plant Protection, Faculty of Agrobiology, Food and Natural Resources, Czech University of Life Sciences Prague, Czech Republic.
\end{abstract}

Current address of second author: Department of Plant Pathology, University of Minnesota, St. Paul.

Accepted for publication 22 June 2017.

\begin{abstract}
Cyclophilins (EC 5.2.1.8) belong to a subgroup of proteins known as immunophilins, which also include FK506-binding proteins and parvulins. Members of the immunophilins have two main characteristic properties: (i) peptidyl-prolyl cis-trans isomerase activity and (ii) the ability to bind immunosuppressant molecules of fungal origin. Cyclophilins are some of the most conserved proteins present in eukaryotes and prokaryotes, and they have been implicated in diverse cellular processes and responses to multiple biotic and abiotic stresses. Cyclophilins have been exploited in humans and plants extensively, but they have only recently received attention in regard to phytopathogens. In Phellinus sulphurascens and species of the genus Leptosphaeria and Phytophthora, high expression of cyclophilins was found to be related to infection. Moreover, recent studies of cyclophilins in certain phytopathogens, such as Magnaporthe oryzae, Botrytis cinerea, Cryphonectria parasitica, and Puccinia triticina, demonstrated their roles as a pathogenicity factors. In addition to pathogenicity, cyclophilins have high affinity for the immunosuppressive drug cyclosporin A, which is a potent antifungal agent. Although cyclophilins are highly conserved in phytopathogens, because they have been less studied, their role remains largely unknown. In this review, we provide detailed information on the cyclophilins in several phytopathogens, including fungi and oomycetes, as well as their role in suppressing plant immunity.
\end{abstract}

Additional keywords: protists, virulence.

Cyclophilins are subgroup of immunophilins, which were firstly described by Handschumacher et al. (1984) more than three decades ago. They belong together with FK506-binding proteins (FKBPs) and parvulin-like protein to the family of immunophilins (Thapar 2015). Although the immunophilin proteins have peptidylprolyl cis-trans activity (PPIase), they are structurally dissimilar. Immunophilins vary in their ability to bind to immunosuppressive drug molecules produced by the fungus Tolypocladium inflatum. Cyclophilins bind to a drug known as cyclosporin A (CsA), FKBPs bind to macrolides, such as FK506 (tacrolimus), and rapamycin and parvulins bind to juglone (Fig. 1) (Hanes 2015; Wang and Heitman 2005).

The roles of cyclophilins have been investigated extensively in plants, humans, and human pathogens. They are involved in protein folding (Taylor et al. 2001), signaling (Lin et al. 2015), transcriptional regulation (Dilworth et al. 2012), pre-mRNA splicing (Horowitz et al. 2002), cell cycle regulation (ArevaloRodriguez and Heitman 2005), hormone signaling (Jing et al.

${ }^{\dagger}$ Corresponding author: K. Singh; E-mail: singh@vurv.cz

(C) 2018 The American Phytopathological Society
2015), vesicular import pathway (Brown et al. 2001), control of both meiosis (Wang et al. 2001) and mitosis (Fujimori et al. 2001), stress responses (Kumari et al. 2015), and fungi and oomycete virulence (Viaud et al. 2002, 2003; Wang et al. 2001). Human cyclophilins have been implicated in various diseases, such as cancer, atherosclerosis, diabetes, and neurodegenerative diseases (Lee and Kim 2010). However, roles of cyclophilins and their functions in phytopathogens, particularly for infection, are largely unknown.

\section{CYCLOPHILINS: A HIGHLY CONSERVED FAMILY}

Cyclophilins are an ancient protein family conserved throughout animal and plant kingdoms (Wang and Heitman 2005). Biochemical and whole genome sequence analyses have led to the identification of a large number of cyclophilins in various organisms. Saccharomyces cerevisiae contains eight cyclophilins (Arevalo-Rodriguez et al. 2004); Caenorhabditis elegans has 16 cyclophilins; Aspergillus nidulans has 11 cyclophilins (Pemberton 2006); and humans have a total of 24 cyclophilins (Galat 2003). There are 29 cyclophilins in Arabidopsis (Kumari et al. 2015), 27 cyclophilins in rice (Kumari et al. 2015), and 49 in Chlamydomonas (23 cyclophilins and 26 
FKBPs) (Vallon 2005) (Table 1). Plants appear to have higher numbers of cyclophilins than other eukaryotes (Kumari et al. 2015; Mainali et al. 2014). However, it is not known whether the presence of multiple members of cyclophilins in an organism provides redundancy to compensate for the loss of any particular member (Kumari et al. 2013).

The identification and characterization of cyclophilins in plant and animal pathogens has progressed since their genomes became available (Gan et al. 2009; Pemberton 2006; Singh et al. 2014). In phytopathogens, genome-wide analyses of cyclophilins were reported only recently (Gan et al. 2009; Singh et al. 2014) (Table 1). The presence of cyclophilins in phytopathogens indicates their potential roles in various cellular processes, including control of transcriptional repression, response to environmental stresses, cell cycle control, regulation of calcium signaling, and hormone signaling (Hanes 2015; Jing et al. 2015; Kumari et al. 2015; SchieneFischer 2015).

\section{FIGURE 1}

Three major families of immunophilins and their respective inhibitors. Cyclophilin binds to cyclosporin A, FKBPs binds to FK506/rapamycin, and parvulin binds to juglone. Cyclosporin A, FK506, and rapamycin and derivatives thereof are commonly used as immunosuppressive drugs.

\section{THE ROLE OF CYCLOPHILIN AS A PATHOGENICITY FACTOR IN FUNGI AND OOMYCETES}

The first cyclophilin (CYP1) studied in phytopathogen was identified in the filamentous ascomycetous fungus Magnaporthe oryzae (Talbot et al. 1993) more than 20 years ago. The Magnaporthe oryzae CYP1 encodes a 215-amino-acid mitochondrial cyclophilin and a 165-amino-acid cytoplasmic cyclophilin (Viaud et al. 2002). This polypeptide organization of CYP1 in Magnaporthe oryzae is consistent with the cyclophilins from Cryptococcus neoformans and Neurospora crassa that encode both mitochondrial and cytoplasmic forms within the same open reading frame (ORF) (Tropschug et al. 1988; Wang et al. 2001). The longer ORF of Magnaporthe oryzae CYP1 encodes a protein of 215 amino acids $(23.5 \mathrm{kD})$, whereas the shorter form is 165 amino acids in length $(17.8 \mathrm{kD})$. The cytosolic form, known as cyclophilin A, was the first cyclophilin discovered in humans (Handschumacher et al. 1984).

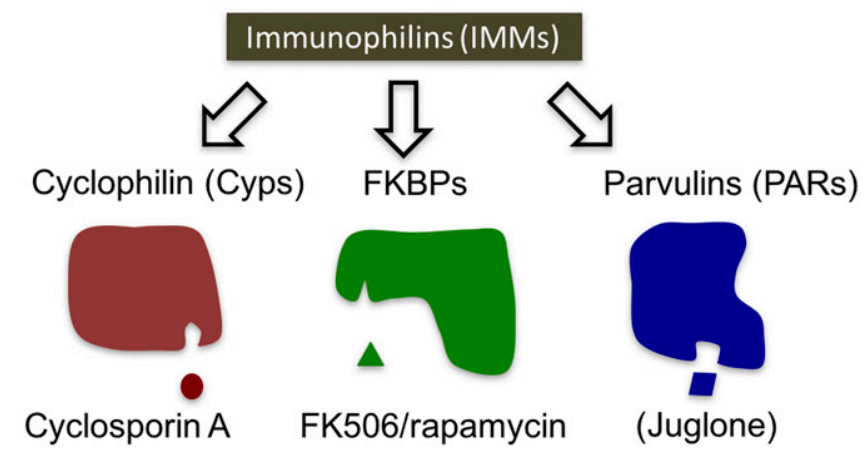

TABLE 1

List of putative cyclophilins in various organisms

\begin{tabular}{|c|c|c|c|}
\hline Taxa & Organisms & Number of cyclophilins & References \\
\hline Mammals & Homo sapiens & 24 & Galat 2003 \\
\hline \multirow[t]{3}{*}{ Plants } & Arabidopsis thaliana & 31 & Kumari et al. 2015 \\
\hline & Glycine max & 62 & Mainali et al. 2014 \\
\hline & Brassica napus & 94 & Hanhart et al. 2017 \\
\hline \multirow{6}{*}{ Fungi } & Neurospora crassa & 9 & Pemberton 2006 \\
\hline & Candida albicans & 6 & Pemberton 2006 \\
\hline & Rhizopus oryzae & 16 & Pemberton 2006 \\
\hline & Ustilago maydis & 9 & Pemberton 2006 \\
\hline & Botrytis cinerea ${ }^{a}$ & 16 & K. Singh, unpublished data \\
\hline & Cryphonectria parasitica $^{\mathrm{b}}$ & 10 & K. Singh, unpublished data \\
\hline Oomycetes & $\begin{array}{l}\text { Phytophthora ( } P \text {. sojae, } P \text {. ramorum, } \\
\text { and } P \text {. infestans) }\end{array}$ & $20-21$ & Gan et al. 2009 \\
\hline Rhizaria & Plasmodiophora brassicae ${ }^{c}$ & 11 & K. Singh, unpublished data \\
\hline
\end{tabular}


In Magnaporthe oryzae, $C Y P 1$ regulates virulence-related functions, including appressorium turgor generation, lipid biosynthesis, and the development of asexual spores (Fig. 2A). Pathogenicity analysis of the $\Delta$ cypl mutant TR33 on rice plants showed threefold reduction in lesion density compared with wild-type plants (Viaud et al. 2002) (Fig. 2A). It was observed that the $\Delta$ cypl mutant was impaired in cuticle penetration compared with wild-type Guy11. However, the $\Delta$ cypl mutant did not influence the vegetative growth of Magnaporthe oryzae, unlike other cyclophilins from various organisms (Arevalo-Rodriguez and Heitman 2005; Berardini et al. 2001; Smith et al. 2009). Conidiogenesis was significantly reduced in the $\Delta$ cypl mutant (approximately threefold) compared with Guy11. Sensitivity to heat shock, starvation, and hyperosmotic stress was unaltered in $\Delta$ cypl compared with Guy11 (Viaud et al. 2002).

Following the identification and characterization of CYP1 in Magnaporthe oryzae, other cyclophilins were identified in Botrytis cinerea (teleomorph Botryotinia fuckeliana), the causal agent of gray mold or botrytis rot on bean and tomato leaves (Viaud et al. 2003). Cyclophilin A in B. cinerea was designated as BCPl and harbors two putative translation initiation codons within the same ORF, potentially encoding two polypeptides, similar to $C Y P 1$ in
Magnaporthe oryzae and cyclophilin from Cryptococcus neoformans (Viaud et al. 2002; Wang et al. 2001). The longer ORF of BCP1 is 223 codons in length and targeted to mitochondria. The shorter form is 181 codons in length, being initiated at codon 43 of the longer ORF and is likely localized in the cytosol (Viaud et al. 2003).

The role of BCP1 in morphogenesis and pathogenicity has been elucidated by disruption of the $B C P 1$ gene. The knockout mutant bcpls was generated and evaluated (Viaud et al. 2003). However, vegetative growth, conidial germination, and conidiogenesis appeared unaltered in the $b c p l \Delta$ strain. Pathogenicity tests with the bcp $1 \Delta$ strain on bean leaves revealed a twofold reduction in disease lesion diameter compared with wild type (Viaud et al. 2002) (Fig. 2A). This indicates that BCP1 is involved virulence-related functions in B. cinerea.

Another fungus in which cyclophilin has been functionally characterized is the ascomycete Cryphonectria parasitica (Chen et al. 2011). Cryphonectria parasitica is the causal agent of chestnut blight or chestnut bark disease. The role of cyclophilin A (cyp1) was investigated by construction of a cypls deletion mutant. Pathogenicity analysis of the knockout mutant cypls resulted in a dramatic reduction $(70 \%)$ in canker size on dormant chestnut stems compared with the wild-type
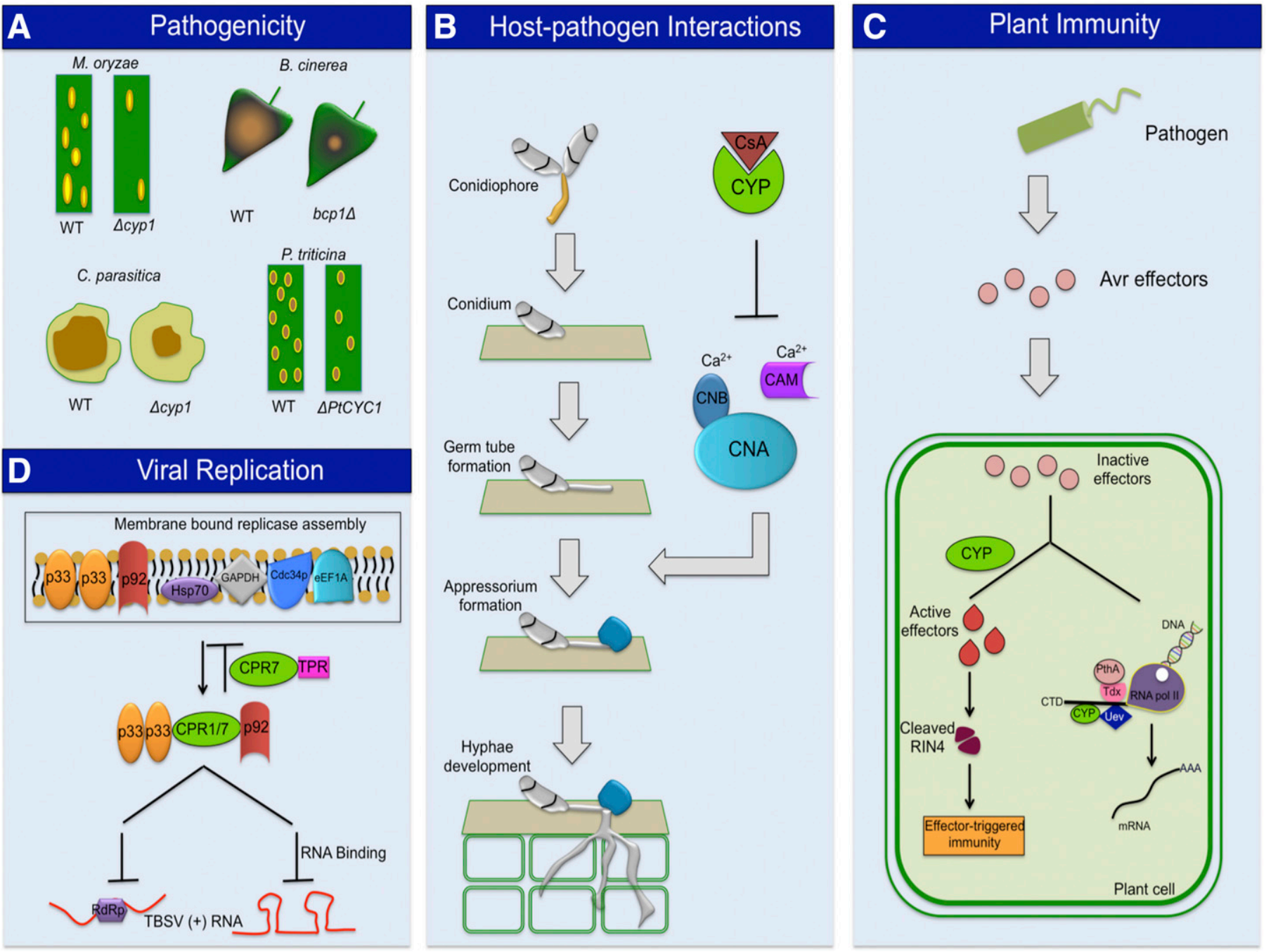

\section{FIGURE 2}

Various roles of cyclophilins in phytopathogens adapted from previous studies. A, The pathogenicity-related roles of cyclophilins are adapted from Viaud et al. (2002) for Magnaporthe oryzae, Viaud et al. (2003) for Botrytis cinerea, Chen et al. (2011) for Cryphonectria parasitica, and Panwar et al. $(2013 a, b)$ in the case of Puccinia tritici. B, Cyclophilins play important roles in host-pathogen interactions in Magnaporthe oryzae. C, Cyclophilins are involved in viral replication. D, Host cyclophilins trigger plant immunity and have functions related to transcription regulation. 
strain EP155 (Chen et al. 2011) (Fig. 2A). However, cypld does not exhibit morphological changes, or changes in conidial production, asexual spore size, and spore germination rates compared with the parental strain (Chen et al. 2011).

Phellinus sulphurascens (Basidiomycetes) is the causal agent of laminar root rot in conifers, one of the most damaging root diseases of trees. Cyclophilin ( $P S C Y P 1$ ) was identified as a ubiquitous protein in Phellinus sulphurascens during mycelia growth. Cyclophilin $P s C Y P 1$ showed significantly high expression at early time points (12 to $35 \mathrm{~h}$ postinfection) during Phellinus sulphurascens infection/colonization of Douglas fir roots. Expression of PsCYPl was higher than 15 other putative virulence-related genes studied (Williams et al. 2014).

The dothideomycete species complex, L. maculans and L. biglobosa, is the causal agent of blackleg disease in oilseed rape (Fitt et al. 2006). Cyclophilins, along with FKBPs, were only recently identified in L. maculans (Singh et al. 2014). L. maculans and L. biglobosa are highly similar and were only recently classified as two independent species (Shoemaker and Brun 2001). L. maculans is highly virulent and causes stem base cankers, in contrast to L. biglobosa, which is weakly virulent, causing mainly upper stem lesions (Fitt et al. 2006; Williams and Fitt 1999). Higher expression of L. maculans cyclophilin A (a homolog to the human CypA) was observed in vitro and in planta compared with L. biglobosa, indicating that this cyclophilin in L. maculans may act as a key component in differentiating the species complex (K. Singh, unpublished data).

In oomycetes, bioinformatic analyses of the genomes of three Phytophthora species, Phytophthora infestans, Phytophthora nicotianae, and Phytophthora sojae, revealed extensive synteny between the 20 or 21 members of the cyclophilin gene family (Gan et al. 2009). The role of Phytophthora cyclophilins has been explored by expression profiling (Gan et al. 2009). Phytophthora sojae, Phytophthora infestans, and Phytophthora nicotianae cyclophilins were significantly expressed at various developmental stages, including during mating and during infection of host plants (Gan et al. 2009).

The two best-known plant-parasitic rhizaria that infect plant crops are Plasmodiophora brassicae and Spongospora subterranea (Burki and Keeling 2014). Plasmodiophora brassicae causes clubroot disease in the family Brassicaceae (Dixon 2009), and $S$. subterranea is the causal agent of powdery scab of potato (Merz and Falloon 2009). Cyclophilins are highly conserved in the genome of Plasmodiophora brassicae (K. Singh, unpublished data). Unfortunately, Plasmodiophora brassicae cannot be cultured in vitro, restricting the development of efficient transformation systems for functional analysis of genes (Hwang et al. 2012). However, Plasmodiophora brassicae gene functions can be studied in heterologous systems (Ma et al. 2014; Mascia et al. 2014). Cyclophilin A from Plasmodiophora brassicae was heterologously expressed in the Magnaporthe oryzae cyclophilin A deletion strain $(\Delta c y p l)$. Restoration of virulence function in the Magnaporthe oryzae mutant indicates a potential role of Plasmodiophora brassicae cyclophilin A in pathogenicity (K. Singh, unpublished data).

\section{CYCLOPHILIN AND ITS ASSOCIATION WITH CYCLOSPORIN A IN PHYTOPATHOGENS}

The identification of the first protein that showed PPIase activity (Fischer et al. 1984) was reported over 30 years ago. The protein was isolated from bovine thymocytes as an intracellular protein with a high affinity for the immunosuppressive drug CsA. CsA is a lipophilic, cyclic undecapeptide produced by the fungus Tolypocladium inflatum. CsA interacts with cyclophilin A in phytopathogenic fungi (Chen et al. 2011; Viaud et al. 2002, 2003) (Fig. 2B). CsA also exhibits potent antifungal and antiviral properties (Cruz et al. 2000; Nakagawa et al. 2004). CsA severely suppresses the vegetative growth of Magnaporthe oryzae and B. cinerea at concentrations of $100 \mu \mathrm{g} / \mathrm{ml}$ (Viaud et al. 2002, 2003). The fungicidal activity of CsA is dependent on cyclophilin. The interaction of cytosolic cyclophilin A with CsA generates a ternary complex that acquires the ability to bind and strongly inhibit calcineurin, a conserved calcium/calmodulin-dependent, serine/ threonine-specific protein phosphatase (Liu et al. 1991). Calcineurin is crucial in the regulation of fungal vitality and morphogenesis (Fox and Heitman 2002; Rasmussen et al. 1994). Protein-protein interactions between cyclophilin A and calcineurin have been suspected in various models (Rasmussen et al. 1994; Wang et al. 2001). In Magnaporthe oryzae, the effect of CsA-mediated calcineurin inhibition has been shown to hinder morphological changes such as appressorium formation and hyphal development (Viaud et al. 2002). In B. cinerea, calcineurin is involved in the maintenance of wild type hyphal morphology and growth, but its inhibition prevents infection-related morphogenesis, suggesting that calcineurin has a role in the first steps of plant infection (Viaud et al. 2003) (Fig. 2B). In addition, the products of some calcineurin-dependent genes ( $C N D$ genes) in $B$. cinerea suggest that calcineurin plays an important role in secondary metabolism and plant-pathogen interactions.

\section{INHIBITION OF RNA REPLICATION IN PLANT VIRUSES BY CYCLOPHILINS}

Some cyclophilins inhibit RNA replication of plant viruses. For example, Cprlp (Saccharomyces cerevisiae cyclophilin A) interacts with the replication protein $\mathrm{p} 33$ of the Tomato bushy stunt virus (TBSV), both in yeast and in vitro. The level of TBSV replicon RNA was elevated in the cprl $1 \Delta$ mutant in yeast, whereas overexpression of Cprlp decreased viral replication (Kovalev and Nagy 2013; Mendu et al. 2010) (Fig. 2C). Another cyclophilin found to be among the strongest inhibitors of TBSV replication in S. cerevisiae is Cpr7p (S. cerevisiae cyclophilin 40) (Lin et al. 2012). Cpr7p (Cyp40-like protein) is a tetratricopeptide repeat (TPR)-containing cyclophilin that was found in yeast and interacts with p33/p92 replication proteins of TBSV. The Cpr7p homolog proteins from Arabidopsis also interact with $\mathrm{p} 33 / \mathrm{p} 92$ replication proteins, and they showed remarkable inhibitory effects on TBSV repRNA accumulation. Thus, the inhibitory effect of Cyp40-like proteins against TBSV is conserved between $S$. cerevisiae and Arabidopsis (Earley and Poethig 2011; Smith et al. 2009). The TPR domain of Cpr7p binds to the RNA-binding region of $\mathrm{p} 33 / \mathrm{p} 92$ replication proteins and thereby inhibits TBSV replication. This would likely inhibit the recruitment of the viral RNA to membranes, where viral replication occurs. In addition, Cpr7p inhibits the assembly of a functional VRC, which then leads to decreased levels of viral RNA synthesis (Lin et al. 2012). Overall, Cyp40-like proteins could be important inhibitors or regulators of various RNA viruses (Lin et al. 2012; Smith et al. 2009).

\section{THE ROLE OF CYCLOPHILINS IN PLANT IMMUNITY}

Phytopathogens can impact plant growth and reproduction, but they also trigger plant immunity. Recognition of pathogens by the innate immune system relies on pathogen-associated molecular patterns (PAMPs), which are perceived by pattern recognition receptors at the plant surface. This response is known as PAMPtriggered immunity (PTI) (Dodds and Rathjen 2010). To colonize plants, pathogens need to overcome PTI. Therefore, phytopathogens secrete a diverse array of effector molecules into plant cells to overcome host plant immunity (Dodds and Rathjen 2010; Jones and Dangl 2006). In return, plants develop a second line of immunity known as effector-triggered immunity (ETI). Pathogens interact with host proteins to modulate plant defenses and achieve successful infection (Day et al. 2006; Mukhtar et al. 2011). Plant cyclophilin is a well-known target for pathogens (Pogorelko et al. 2014) (Fig. 2D). For example, the Pseudomonas syringae cysteine 
protease, AvrRpt2, requires activation by Arabidopsis cyclophilin ROC1 before it cleaves RIN4, which is a negative regulator of plant immunity (Coaker et al. 2005; Liu et al. 2009). Xanthomonas citri transcription activator-like effector PthA proteins (members of the AvrBs3/PthA family) interact with citrus cyclophilin (CsCYP) and activate host transcription by inhibiting the PPIase activity of CsCYP (Domingues et al. 2010, 2012). Grapefruit cyclophilin promotes a conformational change in $A v r G f 2$, thereby triggering the resistance response (Gochez et al. 2017). In Phytophthora sojae, the RXLR effector $A v r 3 b$ is activated by soybean cyclophilin GmCYP1, and is essential for an Rps3b-mediated hypersensitive response (Kong et al. 2015). Therefore, characterization of new effectors by studying their interaction with plant cyclophilins would provide new insights into the plant pathways that are perturbed during the infection process.

In Puccinia triticina, cyclophilin functions, along with those of two other pathogenicity-related genes, an MAP kinase (Hu et al. 2007) and calcineurin B (Cervantes-Chávez et al. 2011), were monitored using Barley stripe mosaic virus host/virus induced gene silencing (BSMV-HIGS/VIGS) (Nowara et al. 2010). Ectopic expression of the Puccinia triticina cyclophilin (PtCYC1), MAP kinase (PtMAPK1) and calcineurin B (PtCNB1) in wheat resulted in the generation of complementary siRNA molecules in leaves. This triggered RNA silencing of the corresponding genes in the colonizing fungus, resulted in disease suppression of wheat leaf rust (Panwar et al. 2013a, b) (Fig. 2A). This suggests that cyclophilins in phytopathogens are involved in attenuation of plant immunity. Deciphering the specific interactions between phytopathogen cyclophilins and the plant immune system might reveal new traits to develop resistant crop plants in the future.

\section{DOMAIN ARCHITECTURE AND EVOLUTION OF CYCLOPHILINS IN PHYTOPATHOGENS}

All cyclophilins carry a domain of approximately 109 aa known as cyclophilin-like domain (CLD) (Wang and Heitman 2005). Cyclophilins in phytopathogens are classified into two major categories: single-domain proteins and multidomain proteins (Gan et al. 2009; Singh et al. 2014). A single-domain protein carries only the single catalytic CLD domain, which occasionally includes a signal peptide directing it to the secretory pathway (Fig. 3). Single-domain cyclophilins, such as cyclophilin A, are abundant in phytopathogens (Singh et al. 2014) (K. Singh, unpublished data).

Multidomain cyclophilins in phytopathogens possess additional similar or distinct functional domains in conjunction with single or multiple catalytic CLDs. The additional domain can be a tetracopeptide repeat (TPR), WD40, an internal repeat domain (RPT), a RNA-binding domain (RNP), or an RNA recognition motif (RRM; a U-box and a glutaredoxin domain). The presence of diverse domains/motifs indicates potential roles for cyclophilins in processes such as protein folding, RNA binding, and interaction with histones (Bannikova et al. 2013; Li et al. 2007; Scheufler et al. 2000; Schiene-Fischer 2015; Taylor et al. 2001) (Fig. 3). A unique class of cyclophilins, which comprised FKBP in the same polypeptide known as FCBP (FK506 and cyclosporinbinding proteins) was identified in Phytophthora (Adams et al. 2005) (Fig. 3).

Domain duplication and shuffling by allele recombination are probably the most important forces driving protein evolution (Vogel et al. 2005), with the majority of multidomain proteins likely to have evolved by stepwise insertion of single-domain proteins (Björklund et al. 2005). Phylogenetic analyses of cyclophilin proteins in four different fungal taxa, Ascomycota, Basidiomycota, Microsporidia, and Zygomycota, revealed that single and multidomain containing cyclophilins appear to have evolved together (Pemberton 2006). Phylogenetic reconstructions of cyclophilin proteins from various phytopathogens, including L. maculans, L. biglobosa, Albugo candida, Albugo laibachii, Hyaloperonospora arabidopsidis, Cochliobolus heterostrophus, Phaeosphaeria nodorum, Pyrenophora tritici-repentis, Mycosphaerella graminicola, Mycosphaerella fijiensis, and Plasmodiophora brassicae, revealed that single-domain and multidomain cyclophilin proteins have coevolved (Fig. 4) (Pemberton 2006; Singh et al. 2014).

\section{DIFFERENCES BETWEEN CYCLOPHILIN A PROTEINS IN PHYTOPATHOGENS AND PLANTS}

Predicted three-dimensional structural model of cyclophilin A (CYPA) from Magnaporthe oryzae, Phellinus sulphurascens, Cryphonectria parasitica, and B. cinerea revealed that they possess similar secondary structure elements like their plant counterparts (Fig. 5) (Coaker et al. 2006; Singh et al. 2014). However,

\section{FIGURE 3}

Domain architecture of cyclophilins in phytopathogens. CLD, cyclophilinlike domain; TPR, tetratricopeptide repeat; SP, signal peptide; RRM, RNA recognition motif; Rtf2, ring finger; and FKBP, FK506-binding proteins. The analysis is based on protein domains present in cyclophilins from dothideomycetes, including the following Pleosporales: Leptosphaeria maculans, Cochliobolus heterostrophus, Phaeosphaeria nodorum, Pyrenophora tritici-repentis; Capnodiales: Mycosphaerella graminicola and Mycosphaerella fijiensis; and Plasmodiophorid: Plasmodiophora brassicae. The domain architecture of FCBP is from

Phytophthora.

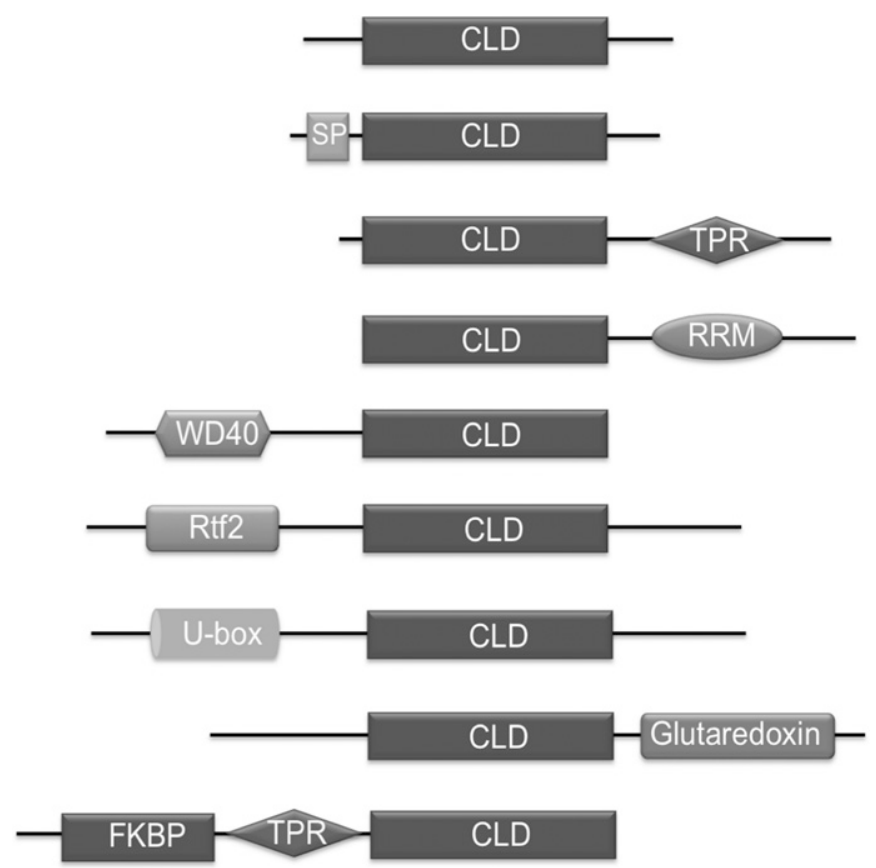


phytopathogen cyclophilins lack a divergent loop, KSGKPLH, which is a distinct feature of plant cyclophilin A (Fig. 5A and B) (Sekhon et al. 2013). It might be possible that effectors molecules recognize plant cyclophilin based on this motif which helps to fold them properly by prolyl isomerization. However, further experimental validation is needed to verify this hypothesis. In phytopathogen cyclophilin A, active site and PPIase residues such as His61, Arg62, Ile64, Phe67, Met68, Gln70, Thr80, Lys89, Aln110, Gln118, Phe120, Trp128, and His133 (position according to Citrus sinensis cyclophilin CsCyp) are highly conserved (Fig. 5C) (Gochez et al. 2017; Sekhon et al. 2013). So far, no studies are available showing whether or not these active sites and PPIase residues play role in effector-cyclophilin binding complex. The role of these active site residues has yet to be established during the effector-cyclophilin binding. In addition, it would be intriguing to understand the interaction affinities of effectors with plant and phytopathogen cyclophilins.

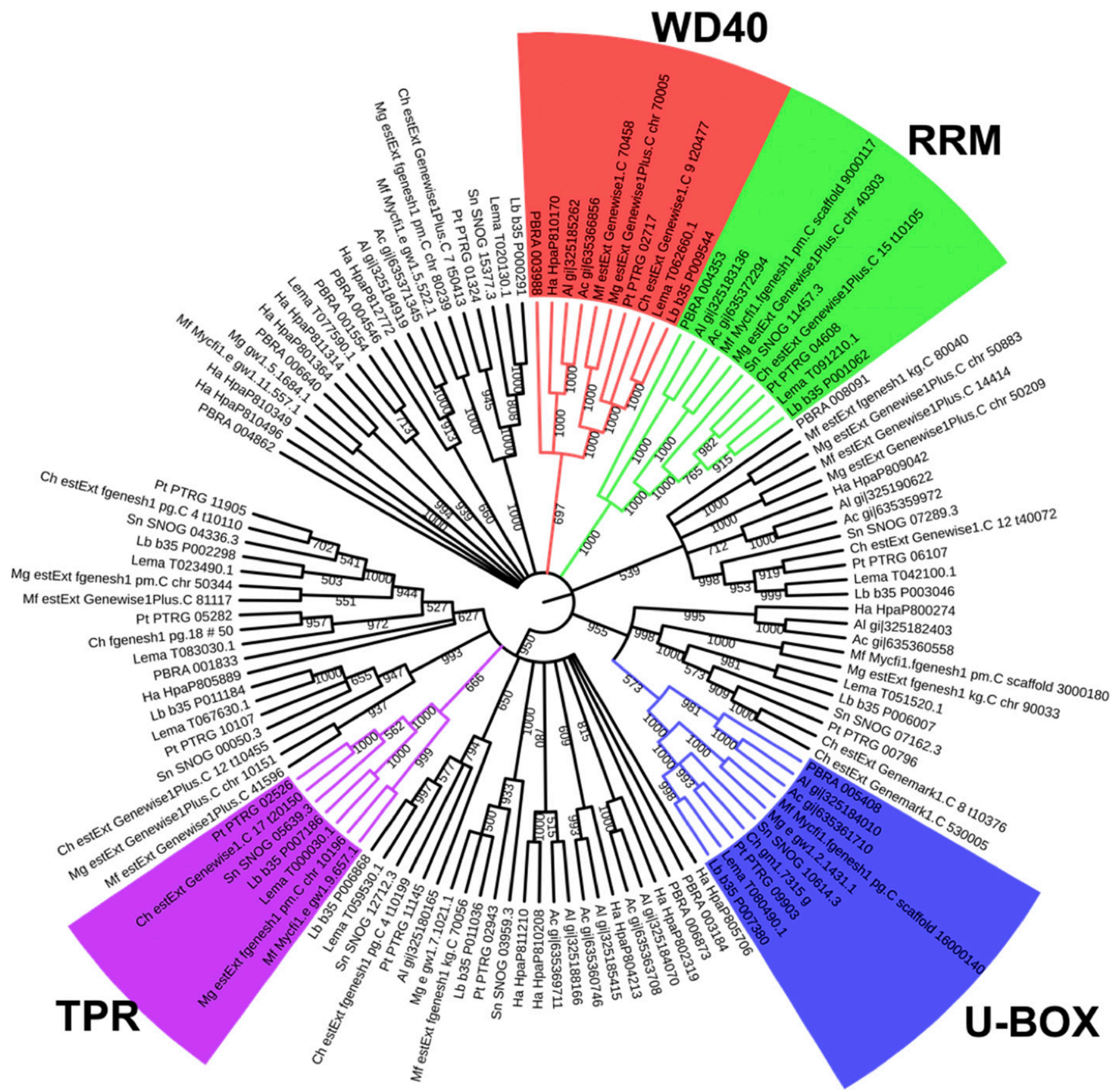

FIGURE 4

Phylogenetic analysis of putative cyclophilins from various dothideomycetes fungi, including the following Pleosporales: Leptosphaeria maculans ('Lema'), Leptosphaeria biglobosa ('Lb'), Cochliobolus heterostrophus ('Ch'), Phaeosphaeria nodorum ('Pn'), Pyrenophora tritici-repentis ('Pt'); Capnodiales: Mycosphaerella graminicola ('Mg') and Mycosphaerella fijiensis ('Mf'); oomycetes: Albugo candida ('Ac'), Albugo laibachii ('Al'), and Hyaloperonospora arabidopsidis ('Ha'); and rhizaria: Plasmodiophora brassicae ('PBRA'). Multidomain proteins are highlighted with different colors; TRP (purple), U-box (blue), WD40 (red), and RRM (green). To generate the phylogenetic tree, protein sequences were aligned using ClustalX2, and the tree was constructed using MEGA7 and viewed with iTOL. The maximum-likelihood method was used for construction of the tree, and the reliability of the branches was inferred from a bootstrap analysis of 1,000 replicates. Bootstrap values above $50 \%$ are shown as numbers. 
Despite the mainly conserved secondary structures in CYP1 of phytopathogens (Fig. 5C), we observed few variations between Magnaporthe oryzae, which lacks the conserved motifs PVLDA[N/ $\mathrm{S}][\mathrm{Y} / \mathrm{G}][\mathrm{R} / \mathrm{K}] \mathrm{PTS}[\mathrm{E} / \mathrm{T}][\mathrm{I} / \mathrm{V}][\mathrm{K} / \mathrm{Q}][\mathrm{V} / \mathrm{E}]$ and $\mathrm{AD}[\mathrm{E} / \mathrm{D}][\mathrm{D} / \mathrm{E}][\mathrm{G} / \mathrm{S}]$ $[\mathrm{R} / \mathrm{L}][\mathrm{R} / \mathrm{M}]$ conserved in Cryphonectria parasitica and $B$. cinerea. Both Magnaporthe oryzae and $B$. cinerea develop specialized infection structures, known as appressoria, to facilitate penetration of the host. In Magnaporthe oryzae, CYP1 influences the cellular turgor generation in appressoria, hyphal growth and development of conidia, while in B. cinerea, cyclophilin BCP1 is required for plant cell penetration and in planta growth during infection (Viaud et al. 2002, 2003). Cryphonectria parasitica CYP1 influences hyphal morphology, conidial production, spore germination rates and asexual spore size although this fungus does not form appressoria (Chen et al. 2011). Therefore, CYP1 plays a role for the development of distinct infection structures in different phytopathogens, which might be related to different protein structures. Further studies are needed to understand the relationships between proteins structure and functions in cyclophilins for the development of infection structures in phytopathogens.

\section{CONCLUSION AND FUTURE PERSPECTIVES}

Cyclophilins are a highly conserved protein family in phytopathogens. The occurrence of cyclophilins in multiple copies highlights their pivotal role in various cellular processes. So far, cyclophilins in phytopathogens have been associated with infection processes and/or virulence. However, unlike their plant and human counterparts, many of the roles of cyclophilins in phytopathogens have not been thoroughly investigated. Deciphering the roles and mechanisms of cyclophilin activity in pathogenicity might be a basis for new phytopathogen control strategies.

Phytopathogen cyclophilins are receptors of the dynamic antifungal agent CsA, which might be a target for the development of novel and effective fungicides. Furthermore, the cyclophilin-CsA complex inhibits calcineurin. Therefore, investigating the downstream
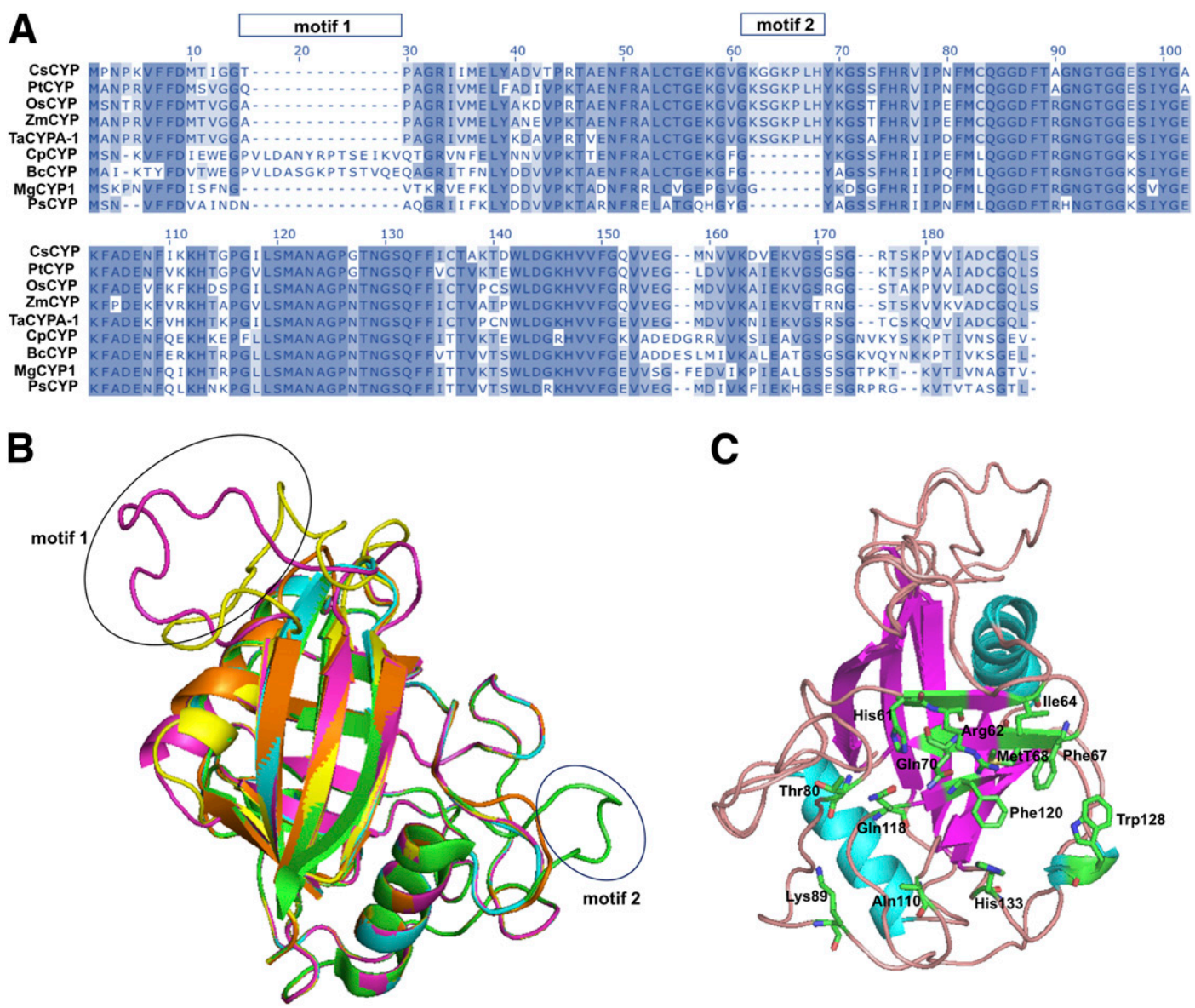

FIGURE 5

A, Multiple sequence alignment of cyclophilin proteins from Citrus sinensis (CsCYP; GenBank accession number AAX94775), Triticum aestivum (TaCYPA-1; GenBank accession number J0678695), Populus trichocarpa (PtCYP; GenBank accession number XM_002313700), Oryza sativa (OsCYP19-2; GenBank accession number NM_001052252), Zea mays (ZmCYP; GenBank accession number BT042680), Magnaporthe oryzae (MgCYP1; GenBank accession number XP_003713349.1), Phellinus sulphurascens (PsCYP1; GenBank accession number AGC93054.1), Cryphonectria parasitica (CpCYP1; GenBank accession number ACl14530.1), and Botrytis cinerea (BcCYP1; GenBank accession number AAQ16572.1) was performed using ClustalX v.2.1 and Jalview 2.10.1 multiple-alignment editor was used for the final presentation. B, Three-dimensional structural model for Magnaporthe oryzae (orange), Phellinus sulphurascens (cyan), Cryphonectria parasitica (yellow), and Botrytis cinerea (magenta) proteins. Structural model threaded onto the crystal structure of Citrus sinensis (PDB ID: 4JJM) (green). C, Superimposed structure model of Magnaporthe oryzae, Phellinus sulphurascens, Cryphonectria parasitica, and B. cinerea proteins. The general structure consists of eight antiparallel beta-sheets (magenta) and three alpha-helices. In phytopathogen cyclophilin A, active site and PPlase residues such as His61, Arg62, Ile64, Phe67, Met68, Gln70, Thr80, Lys89, Aln110, GIn118, Phe120, Trp128, and His133 (position according to Citrus sinensis cyclophilin CsCYP). Homology modeling was performed using ExPasy Swiss-Model. Final models were generated by PyMOL. 
targets of calcineurin may provide additional insight into the molecular basis of fungal pathogenesis and the role of cyclophilins in successful infection. Plant cyclophilin-targeted effectors of bacteria and Phytophthora species suppress plant immunity (ETI). Therefore, host cyclophilins could serve as a basis for the identification of new types of effectors that may alter plant immunity. Understanding cyclophilin-effector interactions might reveal novel signaling pathways involved in phytopathogen attack and host responses (host-pathogen interactions). The similarity in the domain organization of cyclophilins from various phytopathogens reveals that they have coevolved. Furthermore, it would be intriguing to know the role of the additional domains/motifs present in cyclophilins, which might also lead to the discovery of novel roles related to protein folding and RNA binding in phytopathogens.

Although cyclophilins play an important role in phytopathogens, several aspects of their function are still unclear. Therefore, future research should address whether (i) specific pathways are controlled by cyclophilins in different phytopathogens, (ii) the presence of multiple cyclophilin members provides redundancy to compensate for the loss of any member, (iii) additional domains influence the role of cyclophilins, (iv) phytopathogen cyclophilins play a role in hostpathogen interactions, and (v) to determine why effectors interacts with plant cyclophilins instead of phytopathogen cyclophilin? However, studies on the specific roles of these less studied proteins in phytopathogens are still in preliminary stages. Combined functional genomic approaches and gene disruption studies, are anticipated to shed further light on their importance and provide new insights into plant-pathogen interactions.

\section{ACKNOWLEDGMENTS}

K. Singh acknowledges the Ministry of Education, Youth and Sports, the Czech Ministry of Agriculture (grants QJ1310227 and QH81127), EMBO and the Czech University of Life Sciences Prague (grant 20142031). K. Singh is thankful to M.-H. Balesdent for sharing the L. biglobosa genome. We are grateful to H. Stotz and P. L. Samuels for critical comments to the manuscript.

\section{LITERATURE CITED}

Adams, B., Musiyenko, A., Kumar, R., and Barik, S. 2005. A novel class of dual-family immunophilins. J. Biol. Chem. 280:24308-24314.

Arevalo-Rodriguez, M., and Heitman, J. 2005. Cyclophilin A is localized to the nucleus and controls meiosis in Saccharomyces cerevisiae. Eukaryot. Cell 4:17-29.

Arevalo-Rodriguez, M., Wu, X., Hanes, S. D., and Heitman, J. 2004. Prolyl isomerases in yeast. Front. Biosci. 9:2420-2446.

Bannikova, O., Zywicki, M., Marquez, Y., Skrahina, T., Kalyna, M., and Barta, A. 2013. Identification of RNA targets for the nuclear multidomain cyclophilin AtCyp59 and their effect on PPIase activity. Nucleic Acids Res. 41:1783-1796

Berardini, T. Z., Bollman, K., Sun, H., and Poethig, R. S. 2001. Regulation of vegetative phase change in Arabidopsis thaliana by cyclophilin 40. Science 291:2405-2407.

Björklund, A. K., Ekman, D., Light, S., Frey-Skött, J., and Elofsson, A. 2005. Domain rearrangements in protein evolution. J. Mol. Biol. 353:911-923.

Brown, C. R., Cui, D. Y., Hung, G. G., and Chiang, H. L. 2001. Cyclophilin A mediates Vid22p function in the import of fructose-1,6-bisphosphatase into Vid vesicles. J. Biol. Chem. 276:48017-48026.

Burki, F., and Keeling, P. J. 2014. Rhizaria. Curr. Biol. 24:R103-R107.

Cervantes-Chávez, J. A., Ali, S., and Bakkeren, G. 2011. Response to environmental stresses, cell-wall integrity, and virulence are orchestrated through the calcineurin pathway in Ustilago hordei. Mol. Plant-Microbe Interact. 24:219-232.

Chen, M.-M., Jiang, M., Shang, J., Lan, X., Yang, F., Huang, J., Nuss, D. L., and Chen, B. 2011. CYP1, a hypovirus-regulated cyclophilin, is required for virulence in the chestnut blight fungus. Mol. Plant Pathol. 12:239-246.

Coaker, G., Falick, A., and Staskawicz, B. 2005. Activation of a phytopathogenic bacterial effector protein by a eukaryotic cyclophilin. Science 308:548-550.

Coaker, G., Zhu, G., Ding, Z., Van Doren, S. R., and Staskawicz, B. 2006. Eukaryotic cyclophilin as a molecular switch for effector activation. Mol. Microbiol. 61:1485-1496.
Cruz, M. C., Del Poeta, M., Wang, P., Wenger, R., Zenke, G., Quesniaux, V. F., Movva, N. R., Perfect, J. R., Cardenas, M. E., and Heitman, J. 2000. Immunosuppressive and non-immunosuppressive cyclosporine analogs are toxic to the opportunistic fungal pathogen Cryptococcus neoformans via cyclophilin-dependent inhibition of calcineurin. Antimicrob. Agents Chemother. 44:143-149.

Day, B., Dahlbeck, D., and Staskawicz, B. J. 2006. NDR1 interaction with RIN4 mediates the differential activation of multiple disease resistance pathways. Plant Cell 18:2782-2791.

Dilworth, D., Gudavicius, G., Leung, A., and Nelson, C. J. 2012. The roles of peptidyl-proline isomerases in gene regulation. Biochem. Cell Biol. 90:55-69.

Dixon, G. R. 2009. The occurrence and economic impact of Plasmodiophora brassicae and clubroot disease. J. Plant Growth Regul. 28:194-202.

Dodds, P. N., and Rathjen, J. P. 2010. Plant immunity: Towards an integrated view of plant-pathogen interactions. Nat. Genet. 11:539-548.

Domingues, M. N., de Campos, B. M., de Oliveira, M. L., de Mello, U. Q., and Benedetti, C. E. 2012. TAL effectors target the C-terminal domain of RNA polymerase II (CTD) by inhibiting the prolyl-isomerase activity of a CTDassociated cyclophilin. PLoS One 7:e41553.

Domingues, M. N., De Souza, T. A., Cernadas, R. A., de Oliveira, M. L., Docena, C., Farah, C. S., and Benedetti, C. E. 2010. The Xanthomonas citri effector protein PthA interacts with citrus proteins involved in nuclear transport, protein folding and ubiquitination associated with DNA repair. Mol. Plant Pathol. 11:663-675.

Earley, K. W., and Poethig, R. S. 2011. Binding of the cyclophilin 40 ortholog SQUINT to Hsp90 protein is required for SQUINT function in Arabidopsis. J. Biol. Chem. 286:38184-38189.

Fischer, G., Bang, H., and Mech, C. 1984. Determination of enzymatic catalysis for the cis-trans-isomerization of peptide binding in proline-containing peptides. Biomed. Biochim. Acta 43:1101-1111.

Fitt, B. D. L., Brun, H., Barbetti, M. J., and Rimmer, S. R. 2006. World-wide importance of phoma stem canker (Leptosphaeria maculans and L. biglobosa) on oilseed rape (Brassica napus). Eur. J. Plant Pathol. 114:3-15.

Fox, D. S., and Heitman, J. 2002. Good fungi gone bad: The corruption of calcineurin. BioEssays 24:894-903.

Fujimori, F., Gunji, W., Kikuchi, J., Mogi, T., Ohashi, Y., Makino, T., Oyama, A., Okuhara, K., Uchida, T., and Murakami, Y. 2001. Crosstalk of prolyl isomerases, Pin1/Ess1, and cyclophilin A. Biochem. Biophys. Res. Commun. 289:181-190.

Galat, A. 2003. Peptidylprolyl cis/trans isomerases (immunophilins): Biological diversity-targets-functions. Curr. Top. Med. Chem. 3:1315-1347.

Gan, P. H. P., Shan, W., Blackman, L. M., and Hardham, A. R. 2009. Characterization of cyclophilin-encoding genes in Phytophthora. Mol. Genet. Genomics 281:565-578.

Gochez, A. M., Shantharaj, D., Potnis, N., Zhou, X., Minsavage, G. V., White, F. F., Wang, N., Hurlbert, J. C., and Jones, J. B. 2017. Molecular characterization of XopAG effector AvrGf2 from Xanthomonas fuscans ssp. aurantifolii in grapefruit. Mol. Plant Pathol. 18:405-419.

Handschumacher, R. E., Harding, M. W., Rice, J., and Drugge, R. J. 1984. Cyclophilin-A specific cytosolic binding-protein for cyclosporin-A. Science 226:544-547.

Hanes, S. D. 2015. Prolyl isomerases in gene transcription. Biochim. Biophys. Acta 1850:2017-2034.

Hanhart, P., Thieß, M., Amari, K., Bajdzienko, K., Giavalisco, P., Heinlein, M., and Kehr, J. 2017. Bioinformatic and expression analysis of the Brassica napus L. cyclophilins. Sci. Rep. 7:1514.

Horowitz, D. S., Lee, E. J., Mabon, S. A., and Misqteli, T. 2002. A cyclophilin functions in pre-mRNA splicing. EMBO J. 21:470-480.

Hu, G., Kamp, A., Linning, R., Naik, S., and Bakkeren, G. 2007. Complementation of Ustilago maydis MAPK mutants by a wheat leaf rust, Puccinia triticina homolog: Potential for functional analyses of rust genes. Mol. Plant-Microbe Interact. 20:637-647.

Hwang, S.-F., Strelkov, S. E., Feng, J., Gossen, B. D., and Howard, R. J. 2012. Plasmodiophora brassicae: A review of an emerging pathogen of the Canadian canola (Brassica napus) crop. Mol. Plant Pathol. 13:105-113.

Jing, H., Yang, X., Zhang, J., Liu, X., Zheng, H., Dong, G., Nian, J., Feng, J., Xia, B., Qian, Q., Li, J., and Zuo, J. 2015. Peptidyl-prolyl isomerization targets rice Aux/IAAs for proteasomal degradation during auxin signalling. Nat. Commun. 6:7395.

Jones, J. D. G., and Dangl, J. L. 2006. The plant immune system. Nature 444: 323-329.

Kong, G., Zhao, Y., Jing, M., Huang, J., Yang, J., Xia, Y., Kong, L., Ye, W., Xiong, Q., Qiao, Y., Dong, S., Ma, W., and Wang, Y. 2015. The activation of Phytophthora effector Avr3b by plant cyclophilin is required for the Nudix Hydrolase activity of Avr3b. PLoS Pathog :11.

Kovalev, N., and Nagy, P. D. 2013. Cyclophilin A binds to the viral RNA and replication proteins, resulting in inhibition of tombusviral replicase assembly. J. Virol. 87:13330-13342. 
Kumari, S., Joshi, R., Singh, K., Roy, S., Tripathi, A. K., Singh, P., Singla-Pareek, S. L., and Pareek, A. 2015. Expression of a cyclophilin OsCyp2-P isolated from a salt-tolerant landrace of rice in tobacco alleviates stress via ion homeostasis and limiting ROS accumulation. Funct. Integr. Genomics 15:395-412.

Kumari, S., Roy, S., Singh, P., Singla-Pareek, S. L., and Pareek, A. 2013. Cyclophilins: Proteins in search of function. Plant Signal. Behav. 8:e22734.

Lee, J., and Kim, S. S. 2010. Current implications of cyclophilins in human cancers. J. Exp. Clin. Cancer Res. 29:97.

Li, H., He, Z., Lu, G., Lee, S. C., Alonso, J., Ecker, J. R., and Luan, S. 2007. A WD40 domain cyclophilin interacts with histone $\mathrm{H} 3$ and functions in gene repression and organogenesis in Arabidopsis. Plant Cell 19: 2403-2416.

Lin, J. Y., Mendu, V., Pogany, J., Qin, J., and Nagy, P. D. 2012. The TPR domain in the host Cyp40-like cyclophilin binds to the viral replication protein and inhibits the assembly of the tombusviral replicase. PLoS Pathog. 8:e1002491

Lin, Z. L., Wu, H. J., Chen, J. A., Lin, K. C., and Hsu, J. H. 2015. Cyclophilin $\mathrm{A}$ as a downstream effector of PI3K/Akt signalling pathway in multiple myeloma cells. Cell Biochem. Funct. 33:566-574.

Liu, J., Farmer, J. D., Jr Lane, W. S., Friedman, J., Weissman, I., and Schreiber, S. L. 1991. Calcineurin is a common target of cyclophilin-cyclosporin A and FKBP-FK506 complexes. Cell 66:807-815.

Liu, X., Sun, L., Yu, M., Wang, Z., Xu, C., Xue, Q., Zhang, K., Ye, X., Kitamura, Y., and Liu, W. 2009. Cyclophilin A interacts with influenza A virus M1 protein and impairs the early stage of the viral replication. Cell. Microbiol. 11:730-741.

Ma, X.-F., Li, Y., Sun, J.-L., Wang, T.-T., Fan, J., Lei, Y., Huang, Y.-Y., Xu, Y.-J., Zhao, J.-Q., Xiao, S., and Wang, W.-M. 2014. Ectopic expression of resistance to powdery mildew8.1 confers resistance to fungal and oomycete pathogens in Arabidopsis. Plant Cell Physiol. 55:1484-1496.

Mainali, H. R., Chapman, P., and Dhaubhadel, S. 2014. Genome-wide analysis of cyclophilin gene family in soybean (Glycine max). BMC Plant Biol. 14: 282.

Mascia, T., Nigro, F., Abdallah, A., Ferrara, M., De Stradis, A., Faedda, R., Palukaitis, P., and Gallitelli, D. 2014. Gene silencing and gene expression in phytopathogenic fungi using a plant virus vector. Proc. Natl. Acad. Sci. USA 111:4291-4296.

Mendu, V., Chiu, M., Barajas, D., Li, Z., and Nagy, P. D. 2010. Cpr1 cyclophilin and Ess1 parvulin prolyl isomerases interact with the Tombusvirus replication protein and inhibit viral replication in yeast model host. Virology 406:342-351.

Merz, U., and Falloon, R. E. 2009. Review: Powdery scab of potato-increased knowledge of pathogen biology and disease epidemiology for effective disease management. Potato Res. 52:17-37.

Mukhtar, M. S., Carvunis, A.-R., Dreze, M., Epple, P., Steinbrenner, J., Moore, J., Tasan, M., Galli, M., Hao, T., Nishimura, M. T., Pevzner, S. J., Donovan, S. E., Ghamsari, L., Santhanam, B., Romero, V., Poulin, M. M., Gebreab, F., Gutierrez, B. J., Tam, S., Monachello, D., Boxem, M., Harbort, C. J., McDonald, N., Gai, L., Chen, H., He, Y., Vandenhaute, J., Roth, F. P., Hill, D. E., Ecker, J. R., Vidal, M., Beynon, J., Braun, P., Dangl, J. L., and European Union Effectoromics, C. 2011. Independently evolved virulence effectors converge onto hubs in a plant immune system network. Science 333:596-601.

Nakagawa, M., Sakamoto, N., Enomoto, N., Tanabe, Y., Kanazawa, N., Koyama, T., Kurosaki, M., Maekawa, S., Yamashiro, T., Chen, C. H., Itsui, Y., Kakinuma, S., and Watanabe, M. 2004. Specific inhibition of hepatitis C virus replication by cyclosporin A. Biochem. Biophys. Res. Commun. 313: 42-47.

Nowara, D., Gay, A., Lacomme, C., Shaw, J., Ridout, C., Douchkov, D., Hensel, G., Kumlehn, J., and Schweizer, P. 2010. HIGS: Host-induced gene silencing in the obligate biotrophic fungal pathogen Blumeria graminis. Plant Cell 22:3130-3141.

Panwar, V., McCallum, B., and Bakkeren, G. 2013a. Host-induced gene silencing of wheat leaf rust fungus Puccinia triticina pathogenicity genes mediated by the Barley stripe mosaic virus. Plant Mol. Biol. 81: 595-608.
Panwar, V., McCallum, B., and Bakkeren, G. 2013b. Endogenous silencing of Puccinia triticina pathogenicity genes through in planta-expressed sequences leads to the suppression of rust diseases on wheat. Plant J. 73:521-532.

Pemberton, T. J. 2006. Identification and comparative analysis of sixteen fungal peptidyl-prolyl cis/trans isomerase repertoires. BMC Genomics 7:244.

Pogorelko, G. V., Mokryakova, M., Fursova, O. V., Abdeeva, I., Piruzian, E. S., and Bruskin, S. A. 2014. Characterization of three Arabidopsis thaliana immunophilin genes involved in the plant defense response against Pseudomonas syringae. Gene 538:12-22.

Rasmussen, C., Garen, C., Brining, S., Kincaid, R. L., Means, R. L., and Means, A. R. 1994. The calmodulin-dependent protein phosphatase catalytic sub-unit (calcineurin A) is an essential gene in Aspergillus nidulans. EMBO J. 13:2545-2552.

Scheufler, C., Brinker, A., Bourenkov, G., Pegoraro, S., Moroder, L., Bartunik, H., Hartl, F. U., and Moarefi, I. 2000. Structure of TPR domain-peptide complexes: Critical elements in the assembly of the Hsp70-Hsp90 multichaperone machine. Cell 101:199-210.

Schiene-Fischer, C. 2015. Multidomain Peptidyl Prolyl cis/trans Isomerases. Biochim. Biophys. Acta 1850:2005-2016.

Sekhon, S. S., Kaur, H., Dutta, T., Singh, K., Kumari, S., Kang, S., Park, S. G., Park, B. C., Jeong, D. G., Pareek, A., Woo, E. J., Singh, P., and Yoon, T. S. 2013. Structural and biochemical characterization of the cytosolic wheat cyclophilin TaCypA-1. Acta Crystallogr. D Biol. Crystallogr. 69:555-563.

Shoemaker, R. A., and Brun, H. 2001. The teleomorph of the weakly aggressive segregate of Leptosphaeria maculans. Can. J. Bot. 79:412-419.

Singh, K., Zouhar, M., Mazakova, J., and Rysanek, P. 2014. Genome wide identification of the immunophilin gene family in Leptosphaeria maculans: A causal agent of blackleg disease in oilseed rape (Brassica napus). OMICS 18:645-657.

Smith, M. R., Willmann, M. R., Wu, G., Berardini, T. Z., Moller, B., Weijers, D., and Poethig, R. S. 2009. Cyclophilin 40 is required for microRNA activity in Arabidopsis. Proc. Natl. Acad. Sci. USA 106:5424-5429.

Talbot, N. J., Ebbole, D. J., and Hamer, J. E. 1993. Identification and characterization of MPG1, a gene involved in pathogenicity from the rice blast fungus Magnaporthe grisea. Plant Cell 5:1575-1590.

Taylor, P., Dornan, J., Carrello, A., Minchin, R. F., Ratajczak, T., and Walkinshaw, M. D. 2001. Two structures of cyclophilin 40: Folding and fidelity in the TPR domains. Structure 9:431-438.

Thapar, R. 2015. Roles of prolyl isomerases in RNA-mediated gene expression. Biomolecules 5:974-999.

Tropschug, M., Nicholson, D. W., Hartl, F. U., Kölher, H., Pfanner, N., Wachter, E., and Neupert, W. 1988. Cyclosporin A-binding protein (cyclophilin) of Neurospora crassa: One gene codes for both the cytosolic and mitochondrial forms. J. Biol. Chem. 263:14433-14440.

Vallon, O. 2005. Chlamydomonas immunophilins and parvulins: survey and critical assessment of gene models. Eukaryot. Cell 4:230-241.

Viaud, M., Brunet-Simon, A., Brygoo, Y., Pradier, J. M., and Levis, C. 2003. Cyclophilin A and calcineurin functions investigated by gene inactivation, cyclosporin A inhibition and cDNA arrays approaches in the phytopathogenic fungus Botrytis cinerea. Mol. Microbiol. 50:1451-1465.

Viaud, M. C., Balhadere, P. V., and Talbot, N. J. 2002. A Magnaporthe grisea cyclophilin acts as a virulence determinant during plant infection. Plant Cell 14:917-930.

Vogel, C., Teichmann, S. A., and Pereira-Leal, J. 2005. The relationship between domain duplication and recombination. J. Mol. Biol. 346:355-365.

Wang, P., Cardenas, M. E., Cox, C. M., Perfect, J. R., and Heitman, J. 2001. Two cyclophilin A homologs with shared and distinct functions important for growth and virulence of Cryptococcus neoformans. EMBO Rep. 2: 511-518.

Wang, P., and Heitman, J. 2005. The cyclophilins. Genome Biol. 6:226-232.

Williams, H. L., Sturrock, R. N., Islam, M. A., Hammett, C., Ekramoddoullah, A. K. M., and Leal, I. 2014. Gene expression profiling of candidate virulence factors in the laminated root rot pathogen Phellinus sulphurascens. BMC Genomics 15:603.

Williams, R. H., and Fitt, B. D. L. 1999. Differentiating A and B groups of Leptosphaeria maculans, causal agent of stem canker (blackleg) of oilseed rape. Plant Pathol. 48:161-175. 